\title{
Change management in public sector: A case study of gas distribution firm
}

\author{
Alireza Shirvani ${ }^{\mathrm{a}}$, Mashallah Valikhani Dehaghani ${ }^{\mathrm{a}^{*}}$ and Seyed Hassan Mossavi ${ }^{\mathrm{b}}$
}

${ }^{a}$ Assistant Professor, Dehaghan Branch, Islamic Azad University, Esfahan, Iran

${ }^{b}$ M.A student, Department of Public Administration, Islamic Azad University, Dehaghan Branch, Esfahan, Iran

C H R O I C L E ABSTRACT

Article history:

Received January 28, 2013

Received in revised format

1 May 2013

Accepted 3 May 2013

Available online

May 42013

Keywords:

Change management

Kotter model

Gas distribution

\begin{abstract}
This paper considers different approaches for establishment of change management in governmental agencies. The proposed model of this paper uses Kotter's 8-step method in an empirical investigation for a gas distribution firm located in province of Esfahan, Iran. The results of this study reveal that the organization was successful to create sense of urgency, form a powerful coalition, create a vision for change, communicate the vision, create short-term wins and build on the change. However, the organization was not successful on removing obstacles and changes in corporate culture. In addition, the sixth step, create short -term wins, receives the highest rate of success while removing the obstacles maintains the minimum rate of success. Finally, the survey demonstrates that gender and educational background do not have any impact on change management but age, job experience as well as job position influences change management, significantly.
\end{abstract}

(C) 2013 Growing Science Ltd. All rights reserved.

\section{Introduction}

Change in any organization plays an important role on the success of most organizations and there are various methods for making change on organizations (Dunphy \& Stace, 1993; Reiß, 2012). Kotter's method (Kotter, 2007) is believed to be one of the most popular techniques for making change management in organizations. His method consists of eight stages. The first step is associated with creating urgency within organization. In this step, we need to identify potential threats, and develop scenarios, demonstrating what could happen in the future (Gill, 2002). We also need to examine opportunities, which should be, or could be, exploited and we have to start honest discussions, and express dynamic and convincing reasons to get employees talking and thinking. Finally, we have to ask support from customers, outside stakeholders and industry employee to strengthen our argument. 
In the next step, we need to form a powerful coalition and to meet this requirement, we need to identify the true leaders in our organization, ask for an emotional commitment from these key employees and work on team building within the change coalition. Finally, we need to verify our team for weak areas, and ensure that we could reach a good mix of people from various departments and levels within our company.

The third step is associated with creating a vision for change. To do this, we need to determine the values, which are essential to the change, develop a short summary, which captures what we see as the future of the firms, create a strategy to execute the vision, make sure that our change coalition could describe the vision in five minutes or less and finally, practice our "vision speech" more often.

The fourth step is related to communicate the vision, which is associate with what we need to do with our vision and we need to apply our vision to all perspectives of operations from training to performance reviews. In the next step, we need to remove obstacles and we need to identify, or hire, change leaders whose main roles are to deliver the change, identify those employees who are resisting the change, and help them see what's needed and finally, take necessary action to quickly remove barriers.

The six step is associated with create short-term wins, where we look for sure-fire projects that we can apply without help from any strong critics of the change and reward the employees who help us meet the targets. Build on the change is the seventh stage and we set goals necessary objectives to continue building on the momentum we have achieved and finally, anchor the changes in corporate culture is the last step where we talk about progress every chance we get, tell success stories about the change process, and repeat other stories that we hear. We also need to incorporate the change ideals and values when hiring and training new staff, recognizing the key members of our original change coalition, and make sure the rest of the staff including new ones and old employees remember their contributions and create plans to replace all key leaders of change as they change management occur. This would help ensure that their legacy would not be lost or be forgotten.

There are literally various applications of Kotter method in different industries (Burke, 2002; Todnem By, 2005). Sirkin et al. (2005) presented an in-depth discussion on challenges, we face when we intend to perform change management. Choi et al. (2011) investigated top management's work in applying radical change initiatives. Their case confirmed the limitations of the classic top-down technique to radical change in professional firms. They also identified an important paradox: contrary to contemporary change literature prescription, initial managerial success appeared to impair the change process further down the organization. They reported that when mergers were implemented as tools to affect radical change in politically ambiguous environment, management seemed to be limited to initiate change and to take the impact of the scapegoat due to inherent factors in the change process.

Pollack (2012) reviewed a knowledge management program, successfully implemented within an Australian organization, taken an innovative approach to program management, emphasizing visibility, senior management support and leveraging participant enthusiasm, rather than an emphasis on definition and control.

Sujova and Rajnoha (2012) concentrated on a model for management of strategic change including principles of process management and reported that implementation of process management components by realization of strategic changes enabled to reach the increase of business performance. They paid special attention to methodology for management of strategic change in an enterprise, to basic phases and sequential steps in complex management model. Kavanagh and Ashkanasy (2006) investigated the impact of leadership and change management strategy on organizational culture and individual acceptance of change during a merger. 
Penbek et al. (2012) investigated the road map of; pitfalls experienced during; impact and readiness of internal stakeholders involved in a planned organizational change. They explained that effective strategic management need to be agile to enable firms to move quickly in response to new environmental changes, and to replace outdated ideas, which could provide to meet new requirements as they presented themselves. They initiated with a comprehensive review on managing organizational change and impact of strategic management during a planned change. Hence, Bologna Process had highly interdependent duties adapting a qualitative research technique seemed suitable to be able to study this change process in-depth.

Gareis (2010) in an investigation performed an in-depth study on making change on project-based organizations. Aladwani (2001) discussed change management strategies for successful ERP implementation. Pearce and Sims (2002) examined vertical versus shared leadership as predictors of the effectiveness of change management teams by examining of aversive, directive, transactional, transformational, and empowering leader behaviors.

\section{The proposed study}

The proposed study of this paper performs eight-step change management of Kotter (1998, 2007, 2012) for a gas distribution company located in province of Esfahan, Iran. The proposed study performs the investigation among 250 employees who worked for this gas distribution unit. The sample size has been considered as follows,

$$
n=\frac{N \times z_{\alpha / 2}^{2} \times p \times q}{\varepsilon^{2} \times(N-1)+z_{\alpha / 2}^{2} \times p \times q},
$$

where $N$ is the population size, $p=1-q$ represents the yes/no categories, $z_{\alpha / 2}$ is CDF of normal distribution and finally $\varepsilon$ is the error term. Since we have $p=0.5, z_{\alpha / 2}=1.96$ and $N=250$, the number of sample size is calculated as $n=153$. We have adopted Kotter's standard questionnaire consists of 58 question in Likert scale and distributed among 153 employees, randomly. Cronbach alpha has been calculated as 0.967 , which is well above the minimum acceptable level. Table 1 demonstrates some basic statistics associated with eight components.

\section{Table 1}

The results of mean and standard deviation of eight components

\begin{tabular}{clcc}
\hline Question & Component & Mean & Standard deviation \\
\hline 1 & Create Urgency & 3.6 & 0.41 \\
2 & Form a Powerful Coalition & 3.26 & 0.65 \\
3 & Create a Vision for Change & 3.44 & 0.59 \\
4 & Communicate the Vision & 3.099 & 0.67 \\
5 & Remove Obstacles & 2.97 & 0.50 \\
6 & Create Short-term Wins & 3.67 & 0.54 \\
7 & Build on the Change & 3.26 & 0.39 \\
8 & Anchor the Changes in Corporate Culture & 2.98 & 0.71 \\
\hline
\end{tabular}

The results of the survey indicate that "Create Short-term Wins" receives the highest mean followed by "Create Urgency", "Create a Vision for Change" and "Form a Powerful Coalition". In addition, "Anchor the Changes in Corporate Culture" receives the minimum mean follows by "Communicate the Vision".

\section{The results}

In this section, we present details of our findings on testing eight Kotter's components using t-student test summarized in Table 2 as follows, 
Table 2

The results of testing eight Kotter's components $(\mathrm{df}=152)$

\begin{tabular}{clcc}
\hline Question & Component & t-student & Sig. \\
\hline 1 & Create Urgency & 18.24 & 0.000 \\
2 & Form a Powerful Coalition & 4.91 & 0.000 \\
3 & Create a Vision for Change & 9.11 & 0.000 \\
4 & Communicate the Vision & 1.87 & 0.032 \\
5 & Remove Obstacles & -0.80 & 0.788 \\
6 & Create Short-term Wins & 15.14 & 0.000 \\
7 & Build on the Change & 8.23 & 0.000 \\
8 & Anchor the Changes in Corporate Culture & -0.39 & 0.651 \\
\hline
\end{tabular}

The results of t-student reveal that the organization was successful to create sense of urgency, form a powerful coalition, create a vision for change, communicate the vision, create short-term wins and build on the change $(\alpha=5 \%)$. However, the organization was not successful on removing obstacles and changes in corporate culture.

We have also performed Freedman test to rank the effects of different eight stages on change management and Table 3 demonstrates the results of our survey.

\section{Table 3}

The results of ranking the effects of eight Kotter's components $(\mathrm{df}=152)$

\begin{tabular}{clccc}
\hline Question & Component & Freedman mean rank & Freedman test & Sig. \\
\hline 1 & Create Urgency & 5.94 & & \\
2 & Form a Powerful Coalition & 5.48 & & \\
3 & Create a Vision for Change & 3.46 & 382.31 & 0.000 \\
4 & Communicate the Vision & 3.48 & \\
5 & Remove Obstacles & 6.56 & \\
6 & Create Short-term Wins & 4.52 & \\
7 & Build on the Change & 2.94 & \\
\hline 8 & Anchor the Changes in Corporate Culture & & \\
\hline
\end{tabular}

As we can observe from the results of Table 3, the sixth step, "create short term wins", receives the highest rate of success while "remove the obstacles" maintains the minimum rate of success.

Finally, the survey demonstrates that gender and educational background do not have any impact on change management but age, job experience as well as job position influences change management, significantly.

\section{Conclusion}

In this paper, we have presented an empirical investigation to study on the implementing change management in one of gas distribution firms located in province of Esfahan, Iran. The proposed study chose a sample of 153 employees out of 250 people who worked for this unit and realized that six components of Kotter's model had significance impact while two did not. The survey also has disclosed that "create short term wins", has received the highest rate of success while "remove the obstacles" maintained the minimum rate of success. Based the results of our survey, the following suggestions can be made,

1. We need to create the feel for change within the organization. In fact, all employees must have this feeling and intend to cooperate with change management to make the necessary change.

2. We need to build specialists to make the necessary change; the team needs to be capable of making change. 
3. The outlook of change must be encouraging and all employees need to believe that we could reach a better future with change management.

4. We have to explain mission, vision and objectives in the simplest form and simple words so that all employees have good understanding on where we are and where we should go.

5. We need to detect all obstacles and attempt to remove all of them.

6. We need to celebrate all employees' achievements even if they are small. This could create a better sense of cooperation among employees.

7. We have follow up the program, continuously and do not have to give up in the middle of the change management efforts.

8. We have to build a sustainable change management within the organization.

In summary, change management is not something we could do over a night and we need to have cooperation among all employees and people who participate in change management team.

\section{Acknowledgment}

The authors would like to thank the anonymous referees for constructive comments on earlier version of this work, which have contributed to the quality of the work.

\section{References}

Aladwani, A. M. (2001). Change management strategies for successful ERP implementation. Business Process management journal, 7(3), 266-275.

Burke, W. (2002). Organization Change: Theory and Practice. Sage Publications, India.

Choi, S., Holmberg, I., Löwstedt, J., \& Brommels, M. (2011). Executive management in radical change-The case of the Karolinska University Hospital merger. Scandinavian Journal of Management, 27(1), 11-23.

Dunphy, D., \& Stace, D. (1993). The strategic management of corporate change. Human Relations, 46(8), 905-920.

Gareis, R. (2010). Changes of organizations by projects. International Journal of Project Management, 28(4), 314-327.

Gill, R. (2002). Change management--or change leadership?. Journal of change management, 3(4), 307-318.

Kavanagh, M. H., \& Ashkanasy, N. M. (2006). The impact of leadership and change management strategy on organizational culture and individual acceptance of change during a merger. British Journal of Management, 17(S1), S81-S103.

Kotter, J. (1998). Successful change and the force that drives it. Leading organizations: Perspectives for new era, 458-466.

Kotter, J. P. (2007). Leading change: Why transformation efforts fail. Harvard business review, 85(1), 96.

Kotter, J. P. (2012). Leading change. Harvard Business Press.

Penbek, Ş, Zaptçığlu, D., \& Günerergin, M. (2011). The need of effective strategic management during a planned change: An example of bologna change process from a Turkish university. Procedia - Social and Behavioral Sciences, 24, 649-662

Pollack, J. (2012). Transferring knowledge about knowledge management: Implementation of a complex organisational change programme. International Journal of Project Management, 30(8), 877-886. 
Pearce, C. L., \& Sims, H. P. (2002). Vertical versus shared leadership as predictors of the effectiveness of change management teams: An examination of aversive, directive, transactional, transformational, and empowering leader behaviors. Group Dynamics, 6(2), 172-197.

Reiß, M. (2012). Change Management. BoD-Books on Demand.

Sirkin, H. L., Keenan, P., \& Jackson, A. (2005). The hard side of change management. Harvard Business Review, 83(10), 108.

Sujova, A., \& Rajnoha, R. (2012). The management model of strategic change based on process principles. Procedia - Social and Behavioral Sciences, 62(24), 1286-1291.

Todnem By, R. (2005). Organisational change management: A critical review. Journal of Change Management, 5(4), 369-380. 